\title{
Aortic Regurgitation After Transcatheter Aortic Valve Replacement: Is it a Fall from Grace or Just a Storm in a Teacup?
}

\author{
Marco A. Magalhães ${ }^{1}$, Ron Waksman², Augusto D. Pichard ${ }^{3}$
}

A decade of great enthusiasm has emerged after the first-in-man, successful transcatheter aortic valve replacement (TAVR) report in 2002. Subsequently, the results of the pivotal randomized Placement of AoRTic TraNscathetER (PARTNER) trial were instrumental for the TAVR approval as the standard of care for symptomatic inoperable aortic stenosis. ${ }^{1}$ This 10-year successful history had major drawbacks that were mostly related to the procedure and overcome, in part, by technique and device refinements. Although the short-term outcomes have improved $(<10 \%)$, the long-term mortality post-TAVR has not changed over time. ${ }^{2-5}$ Moreover, the high incidence and the association of post-TAVR aortic regurgitation with mortality have been raising concerns. ${ }^{6,7}$ However important methodological considerations across these studies hamper the understanding of whether this phenomenon represents a "fall from grace" or just a "storm in a teacup".

\section{See page 103}

The reported incidence of aortic regurgitation postTAVR ranges from $50 \%$ to $85 \%$ and derives mostly from echocardiographic data. ${ }^{8}$ The aortic regurgitation can be either central or paravalvular (leak) in origin and graded according to quantitative or semi-quantitative parameters. But none of these methods were prospectively validated nor consensually standardized by the Valve Academic Research Consortium. ${ }^{9}$ Ack nowledging these limitations, apparently more than mild aortic regurgitation post-TAVR has been associated with worse long-term outcomes in different studies with a pooled hazard ratio of 2.27 [95\% confidence interval $(95 \% \mathrm{Cl})$ : 1.84 2.81] at 1 year. $^{7}$ Nonetheless, the most intriguing data came from PARTNER trial (Cohort A) where even mild aortic regurgitation post-TAVR was related to a higher mortality and a real gradient effect was demonstrated. ${ }^{6}$

The manuscript published by Lluberas et al. ${ }^{10}$ in this issue of Revista Brasileira de Cardiologia Invasiva adds important post-TAVR paravalvular aortic regurgitation data based upon a retrospective analysis of 112 $(68.8 \%)$ symptomatic aortic stenosis patients treated with Medtronic CoreValve ${ }^{\circledR}$ (Medtronic, Minneapolis, USA) device, mostly at a single pioneer center in Brazil. The authors reported a frequency of $56 \%$ of post-procedural paravalvular aortic regurgitation. Of these, $41 \%$ were mild and $11.6 \%$ moderate. No severe paravalvular aortic regurgitation was noted. This incidence is similar to the literature but in the lower range for the CoreValve ${ }^{\circledR}$ studies $(9 \%$ to $21 \%) .{ }^{11}$ The incidence of moderate or severe paravalvular aortic regurgitation interesting finding may be related to a more liberal use of balloon postdilatation (34\%). Although underpowered for clinical end-points, no mortality difference was observed at one-year follow-up comparing the moderate paravalvular aortic regurgitation to mild or no aortic regurgitation $(7.7 \%$ vs. $8.1 \%$, respectively; $\mathrm{P}=\mathrm{NS})$.

This finding highlights the conflicting evidence surrounding the post-TAVR aortic regurgitation mortality association. Numerous studies have shown the association of aortic regurgitation post-TAVR and mortality but important analytical and methodological considerations such as the proportional hazard function, the survivorship bias, the lack of standardized definition criteria, the timing and inherent limitations of echocardiographic evaluation and the limited data provided by independent echo core lab diminish the strength of this association. All together, these considerations mitigate the establishment of a direct causal relationship. In other 
words, the link between post-TAVR aortic regurgitation and mortality can be mediated or moderated by either measured or unmeasured confounders and thus is far from being closed. In this arguing line, Lluberas et al. ${ }^{10}$ provide a further insight into the theme by modeling the baseline determinants of paravalvular aortic regurgitation post-TAVR. But, the limited event number ( $\mathrm{n}=$ 13) most likely over-fitted the model and the estimates. Interestingly, the only independent echocardiographic baseline predictor was the presence of left ventricular ejection fraction $<35 \%$ [odds ratio $(\mathrm{OR}): 4.16, \mathrm{Cl}$ : 1.01 $17.0 ; P=0.048]$ which is comparable to the core lab based longitudinal study from PARTNER trial pointing out for a baseline ventricular remodeling difference in patients who develop post-TAVR aortic regurgitation. ${ }^{12}$ Moreover, this study has documented that the post-TAVR aortic regurgitation remains mostly unchanged during the 2 years fol low-up. This is somehow in line with the native chronic aortic regurgitation natural history studies. The long-term survival of volume overload of chronic moderate aortic regurgitation is remarkably good and the mortality is associated with symptoms development and hinges on the clear documentation of the left ventricular remodeling parameters. ${ }^{13}$ Conversely, the studies that showed a higher mortality aortic regurgitation post-TAVR failed to demonstrate aortic regurgitation progression over time, left ventricular remodeling or worsening of functional class symptoms.

Nevertheless, independent of whether or not the post-TAVR aortic regurgitation is a mediator or moderator of poor outcomes, this data underscores the actual procedural limitation and the window of oppor-tunity to improve the technology. Advances in the new TAVR devices are ongoing and include modifications that will limit effectively or eliminate the aortic regurgitation post-TAVR.${ }^{14}$ For now the best strategy is to adopt preventive measures to reduce the incidence of aortic regurgitation such as selecting the adequate size and prosthesis for each patient. One important developing area is the understanding of aortic-valve complex through the multimodality image analysis. ${ }^{15}$ These studies focused on the annulus and against the prior belief of a simple circular, compliant and static structure geometry, the current knowledge about this "virtual" ovoid ring is far beyond the possibility of a single dimension analysis. Recently, the forth dimension was added to the annulus measurement - the time and confirmed the dimension variability according to the cardiac cycle phase. ${ }^{16}$ Herein, the incorporation of the multidimensional analysis by means of multidetector computer tomography and two dimensional/three dimensional echocardiogram has proven to be useful.

The advent of TAVR has transformed the aortic stenosis treatment and forced the Interventional Cardiology to re-engineering not only our labs but also the way in which we interact with the different components of a functioning heart-team with the aim of improving patient prognosis. Whether the aortic regurgitation
post-TAVR represents a real "fall from grace" or just a "storm in a teacup" is still unknown. Further studies designed specifically to answer this question are warranted to ensure the TAVR future potential application on intermediate and low-risk populations.

\section{CONFLICT OF INTEREST}

Augusto D. Pichard is proctor for Edwards Lifesciences. Marco A. Magalhães and Ron Waksman have no conflict of interest to declare.

\section{REFERENCES}

1. Leon MB, Smith CR, Mack M, Miller DC, Moses JW, Svensson LG, et al. Transcatheter aortic-valve implantation for aortic stenosis in patients who cannot undergo surgery. $N$ Engl J Med. 2010;363(17):1597-607.

2. Moat NE, Ludman $P$, de Belder MA, Bridgewater B, Cunningham $A D$, Young $C P$, et al. Long-term outcomes after transcatheter aortic valve implantation in high-risk patients with severe aortic stenosis: the U.K. TAVI (United Kingdom Transcatheter Aortic Valve Implantation) Registry. J Am Coll Cardiol. 2011;58(20):2130-8.

3. Gilard M, Eltchaninoff $\mathrm{H}$, lung B, Donzeau-Gouge P, Chevreul K, Fajadet J, et al. Registry of transcatheter aortic-valve implantation in high-risk patients. N Engl J Med. 2012;366(18):1705-15.

4. Thomas M, Schymik G, Walther T, Himbert D, Lefevre T, Treede $\mathrm{H}$, et al. One-year outcomes of cohort 1 in the Edwards SAPIEN Aortic Bioprosthesis European Outcome (SOURCE) registry: the European registry of transcatheter aortic valve implantation using the Edwards SAPIEN valve. Circulation. 2011;124(4):425-33.

5. Tamburino C, Capodanno D, Ramondo A, Petronio AS, Ettori F, Santoro G, et al. Incidence and predictors of early and late mortality after transcatheter aortic valve implantation in 663 patients with severe aortic stenosis. Circulation. 2011; 123(3):299-308

6. Kodali SK, O'Neill WW, Moses JW, Williams M, Smith CR, Tuzcu $M$, et al. Early and late (one year) outcomes following transcatheter aortic valve implantation in patients with severe aortic stenosis (from the United States REVIVAL trial). Am J Cardiol. 2011;107(7):1058-64.

7. Athappan G, Patvardhan E, Tuzcu EM, Svensson LG, Lemos PA, Fraccaro C, et al. Incidence, predictors, and outcomes of aortic regurgitation after transcatheter aortic valve replacement: meta-analysis and systematic review of literature. J Am Coll Cardiol. 2013;61(15):1585-95.

8. Lerakis S, Hayek SS, Douglas PS. Paravalvular aortic leak after transcatheter aortic valve replacement: current knowledge. Circulation. 2013;127(3):397-407.

9. Leon MB, Piazza N, Nikolsky E, Blackstone EH, Cutlip DE, Kappetein AP, et al. Standardized endpoint definitions for transcatheter aortic valve implantation clinical trials: a consensus report from the Valve Academic Research Consortium. Eur Heart J. 2011;32(2):205-17.

10. Lluberas S, Siqueira D, Costa Jr. JR, Abizaid A, Ramos A, Le Bihan D, et al. Análise da incidência e preditores clínicos e ecocardiográficos do refluxo paraprotético aórtico após o implante de prótese aórtica transcateter. Rev Bras Cardiol Invasiva. 2013;21(2):103-8.

11. Généreux P, Head SJ, Hahn R, Daneault B, Kodali S, Williams $M R$, et al. Paravalvular leak after transcatheter aortic valve replacement: the new Achilles' heel? A comprehensive review of the literature. J Am Coll Cardiol. 2013;61(11):1125-36. 
12. Hahn RT, Pibarot P, Stewart WJ, Weissman NJ, Gopalakrishnan D, Keane MG, et al. Comparison of transcatheter and surgical aortic valve replacement in severe aortic stenosis: a Longitudinal Study of Echocardiography Parameters in Cohort A of the PARTNER Trial (Placement of Aortic Transcatheter Valves). J Am Coll Cardiol. 2013;61(25):2514-21.

13. Bonow RO, Lakatos E, Maron BJ, Epstein SE. Serial long-term assessment of the natural history of asymptomatic patients with chronic aortic regurgitation and normal left ventricular systolic function. Circulation. 1991;84(4):1625-35.

14. Binder RK, Rodes-Cabau J, Wood DA, Mok M, Leipsic J, De Larochelliere $\mathrm{R}$, et al. Transcatheter aortic valve replacement with the SAPIEN 3: a new balloon-expandable transcatheter heart valve. JACC Cardiovasc Interv. 2013;6(3):293-300.

15. Bloomfield GS, Gillam LD, Hahn RT, Kapadia S, Leipsic J, Lerakis $\mathrm{S}$, et al. A practical guide to multimodality imaging of transcatheter aortic valve replacement. JACC Cardiovasc Imaging. 2012;5(4):441-55.

16. Hamdan A, Guetta V, Konen E, Goitein O, Segev A, Raanan $\mathrm{E}$, et al. Deformation dynamics and mechanical properties of the aortic annulus by 4-dimensional computed tomography: insights into the functional anatomy of the aortic valve complex and implications for transcatheter aortic valve therapy. J Am Coll Cardiol. 2012;59(2):119-27. 